Article

\title{
Small Landowner Production of Pellets from Green, Beetle-Killed, and Burned Lodgepole Pine
}

\author{
Xuexian Qin $^{1}$, Robert F. Keefe ${ }^{1, *(1)}$ and Daren E. Daugaard ${ }^{2}$ \\ 1 Forest Operations Research Lab, University of Idaho, 875 Perimeter Drive, Moscow, ID 83844, USA; \\ qin4680@vandals.uidaho.edu \\ 2 Burning Oak Energy, Rolla, MO 65401, USA; dd@burningoakenergy.com \\ * Correspondence: robk@uidaho.edu; Tel.: +1-208-310-0269
}

Received: 17 February 2018; Accepted: 12 March 2018; Published: 14 March 2018

\begin{abstract}
To meet the growing need for raw materials to produce pellets and wood-based biofuels, trees killed by natural disturbances have increasingly been considered as potential feedstock in bioenergy development scenarios in the Western U.S. and Canada. While much research has focused on utilization of beetle-killed and fire-salvaged timber from federal lands in this region, small private landowners make up a large portion of land holdings in the Rocky Mountain Region and may also provide an important potential supply of uniform feedstock pellets in decentralized energy supply systems in the future. In this paper, we evaluated the quality of pellets produced from green, beetle-killed, and burned lodgepole pine with and without bark using a chipper, hammer mill, and pellet mill intended for use by small landowners. Results show that green, beetle-killed, and fire-salvaged lodgepole pine produced by small landowners, including material with bark, are suitable as feedstock for pellet production. Further, pellet quality can be varied through the blending of source lodgepole pine products when needed to meet pellet quality standards.
\end{abstract}

Keywords: biofuels; beetle kill; fire salvage; bark; durability; ash content; calorific value

\section{Introduction}

Wood pellets have been increasingly developed in Northern America for export to meet Europe's demand for renewable energy over the last ten years and demand for exports from the U.S. to China and other Asian markets is expected to increase. To meet the growing supply needs for pellet producers, other raw materials that could be used to produce pellets need to be evaluated. Trees killed by natural disturbances such as wildfires and insect epidemics have been increasingly considered as biomass energy resources in the Western United States [1]. As wood-based biomass markets continue to develop, pellet mills and biofuel facilities may need to draw feedstock from mixed sources that include not only logging residues but also stem materials from thinning operations, salvage operations following beetle outbreaks in lodgepole pine stands, and post-fire salvage logging.

Infestations of bark beetles have impacted over 17 million ha of U.S. forests since 1996 [2]. Infestations throughout the Northern Rocky Mountains have resulted in large volumes of low-value dead wood. In Canada, total cumulative losses from the outbreak are estimated to be more than 700 million cubic meters of the merchantable pine volume by 2017 [3]. Bogdanski et al. [4] indicated that the mountain pine beetle (MPB) epidemic is one important driver of the development of wood pellet production and international export of pellets. A positive use of beetle-killed wood that may also help to reduce wildland fire frequency and intensity while helping to restore fire regimes to forest ecosystems in the west is the transfer of this material to renewable fuel production. Salvage logging also has the potential to influence tree seedling recruitment, affect stand development and fuel loads, and alter potential fire behavior for over one century [5]. Large-scale salvage for MPB has both positive 
and negative effects on biodiversity [6-8], so specific actions should be taken when managing stands after beetle outbreaks. Wildland fire in both healthy and MPB-affected stands regularly results in large volumes of reduced-value sawlog material. It is generally accepted that trees salvaged within one or two years after fire may be used for lumber production. However, lodgepole pine wood resulting from salvage logging more than two years post-fire may be better used to produce bioenergy due to the presence of charcoal [9]. Fire-killed ponderosa pine in Colorado has been recognized as a high-quality source of bioenergy [10]. Harvesting salvaged trees may also benefit stand regeneration [11]. However, post-fire salvage can affect habitat for some species of wildlife, and may affect species composition [8]. The salvage activities may lead to soil disturbance, water yield, erosion, and sediment yield [8]. Therefore, timing and intensity of salvage logging should be planned carefully.

Beetle-killed timber and fire-salvaged timber are major potential feedstock in the Western U.S. and Canada. Jacobson et al. [12] showed that a small pellet mill (drawing approximately 181,437 Bone Dry Ton (BDT) year ${ }^{-1}$ of forest residues from a biorefinery) is a good option for many towns in the Idaho (ID), Montana (MT), and eastern Washington (WA) regions because it is a cost-effective method to produce feedstock for the bioenergy industry. Pellets produced locally could be used directly for heat and power domestically or exported to Asia or Europe for conversion to heat or electricity. They can also eventually be turned into fuel as wood-based biofuel technology and markets continue to develop. Much current research has focused on federal- and industrial-scale utilization of this resource. However, private landowners make up a large portion $(30 \%)$ of land holdings in the Western U.S., with $25 \%$ of private land holdings smaller than $20 \mathrm{Ha}$ [13]. Pellets produced from small landowner properties may be an important component of a uniform feedstock densified biomass in the future in decentralized energy supply systems. In particular, small landowners may fill local niches in the supply chain in the Northern Rocky Mountains, especially where small renewable energy projects such as wood-fired boilers for schools and other public facilities occur. Private forests provided 88\% of the nation's timber harvest in 2011 [13] and are an important component of current sawlog production in operational forestry in the Inland Northwestern United States. Many small landowners may be interested in the potential for producing pellets on their own, using a variety of biomass production equipment that is now available for low-throughput operation. However, it is unknown whether production of pellets at the scale of individual landowners can generate pellets of suitable quality for subsequent bioenergy uses according to conventional pellet standards. The public generally supports local, small-scale bioenergy production projects, particularly when these help to improve forest health [14]. Understanding the potential quality of pellets produced using small-scale equipment, as well as the machine costs associated with processing feedstock locally, are both important for determining the economic viability of small-scale production. This is relevant not only for pellet production as a final processing step, but for when pellets are subsequently used to produce biofuels [15]. In this paper, we examine the quality of wood pellets produced from green, beetle-killed, and post-fire (burned) lodgepole pine with and without bark using a chipper, hammer mill, and pellet mill sized for small landowners. We further evaluate their potential fuel yield as intermediate feedstock for biofuel production by a commercial biofuel producer.

Traditionally, raw materials for wood pellets do not contain bark. In order to maximize use of the raw material to meet increasing demand for wood pellets and decrease production costs, it is meaningful to use the whole logs, without debarking, to produce pellets [16,17].

Recently, pellet production from bark has been studied and reported [16,18-20]. Bark is a suitable raw material for pellet production [20] but pelleting chipped logs with bark may cause uncertainty in pellet quality due to heterogeneity in bark content. The percentage of bark on lodgepole pine trees varies from base to top and pine bark consists of different ratios of cellulose, lignin, and extractives than does stem wood [21,22]. Some studies have indicated that bark had higher mineral content than stem wood, resulting in higher ash content than white wood [23]. Increasing the bark content of pellets may increase pellet ash content following combustion [16]. When bark is added in the raw material to produce pellets, it has a tendency to sinter during combustion $[16,19,20]$ and cause problems for 
combustion devices [24]. However, bark content in pellets may have a positive effect on heat yield (calorific value) of pellets due to the increased content of lignin and extractives [16,21,22].

The mechanical durability of pellets may also be affected by inclusion of bark in feedstocks. Lehtikangas [20] compared pellets made from sawdust, bark, and logging residues and indicated that bark pellets had the highest durability due to the high lignin and extractive content. Filbakk et al. [16] also indicated that pure bark pellets had the best mechanical properties compared with pellets made from mixed wood and bark. As lignin and extractive content reaches above a threshold level, the durability of pellets decreases [25].

Beetle-killed lodgepole pine can be used to produce pellets of comparable quality to green wood pellets [26]. Wood from infested trees tends to have lower moisture content [27-29] and lower lignin and hemicellulose contents than green wood from sound lodgepole pine [27]. However, beetle impacts are not associated with changes in either the calorific value or density of pellets [26]. Large proportions of charcoal on the stem and wood decay associated with fire may increase the ash content of wood pellets produced from fire-salvaged trees [30]. However, past studies have shown no difference among the calorific values between living green trees without bark and fire-killed trees without bark $[1,10]$.

In the processing of wood pellets, there are several factors that may affect the quality of pellets: tree species [18,25], moisture content of raw materials [31-34], particle size and its distribution [20,32,34], pelletizing temperature and pressure [32-36], and binders [37]. Moisture affects binding agents in the pelleting process and has a positive effect on pellet durability, but moisture contents that are too high may reduce pellet quality [20]. By adding steam during the production process, the durability of pellets increased partly due to the high moisture content [16] and high temperature $[33,38,39]$. Therefore, in order to consistently produce pellets that are high quality, both the pre-treatment and pelletization process should be optimized.

\section{Materials and Methods}

\subsection{Materials}

Green and beetle-killed lodgepole pine stems similar to those shown in Figure 1a were harvested in the Slate Creek drainage approximately $8 \mathrm{~km}$ northeast of Riggins, ID $(45.5369,-115.0008)$. The length of the logs varied from $5 \mathrm{~m}$ to $10 \mathrm{~m}$ and the diameters were between $10 \mathrm{~cm}$ and $21 \mathrm{~cm}$. Logs were transported to the University of Idaho Forest Operations Research Lab in Princeton, ID on a self-loading log truck and were decked and allowed to dry for two months before treatment. Five green logs and five beetle-killed logs were transported by forwarder to the East Hatter Creek Unit of the University of Idaho Experimental Forest and were burned for a consistent $60 \mathrm{~min}$ in slash piles to simulate fire-salvaged logs (Figure 1b). Logs were placed on the pile such that one end of each $\log$ was allowed to be directly consumed by the flames, and they were then rotated after $30 \mathrm{~min}$. The fire had flame lengths measuring 2-3 m.

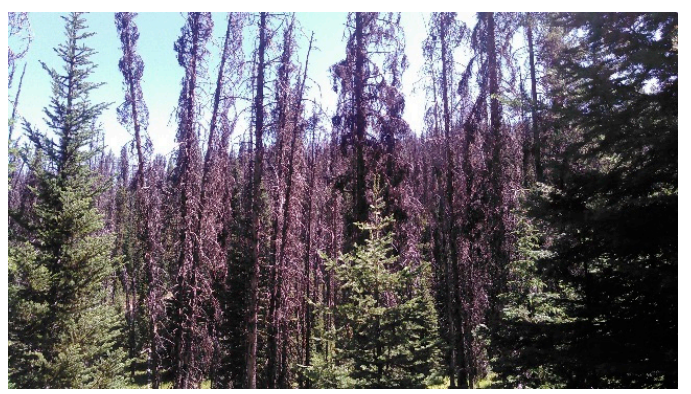

(a)

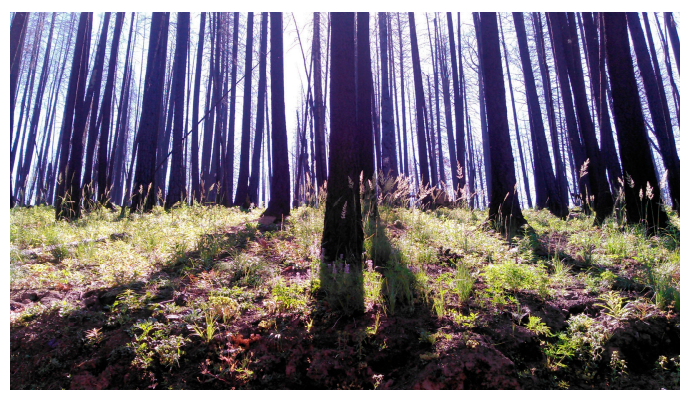

(b)

Figure 1. (a) Mountain pine beetle (MPB)-killed lodgepole pine stands in the Slate Creek drainage on the Nez Perce-Clearwater National Forest; (b) A portion of the 96,000 acre ( 38,800 ha) Tepee Springs Fire, also at Slate Creek, which burned through the area in 2015. 
Half of the green and treated logs were then transported to Stimson Lumber in Plummer, ID for debarking. They were then chipped using a gas-powered 46 HP Morbark Eager Beaver self-feeding chipper (Morbark, LLC, Winn, MI, USA) with $22.9 \mathrm{~cm}$ infeed capacity. Chips were processed using a 22 HP CF420 diesel-powered hammer mill with $6 \mathrm{~mm}$ sieve size, after which the comminuted feedstock was air-dried to $10-12 \%$ moisture content (wet basis). To air-dry, sawdust was spread out on the floor at Composite Materials and Engineering Center at Washington State University at a constant temperature of $21^{\circ} \mathrm{C}$. Moisture content was tested using a moisture meter from Harry W. Dietery Co. (Detroit, MI, USA) and a Sartorius analytical balance (Sartorius Stedim Biotech, Aubagne, France). The formula for determining moisture content was as follows:

$$
\mathrm{MC}=(\mathrm{W} 1-\mathrm{W} 2) / \mathrm{W} 1 \times 100 \%
$$

where MC is moisture content, W2 is the sample weight after being dried, and W1 is the sample weight before being dried. For each of the eight treatment combinations, sawdust was stored in a trash bin with two layers of sealed plastic bags. A Power-Take-Off (PTO) pellet mill (Make Your Own Pellets, LLC, Londonderry, NH, USA) attached to the 3-point hitch of a 60 HP Farmall 560D diesel tractor (Case IH, Racine, WI, USA) was used for pelletization. The processes used by small landowners to produce pellets from standing trees using small-scale harvesting equipment similar to that modeled in our cost analysis are shown in Figure 2.

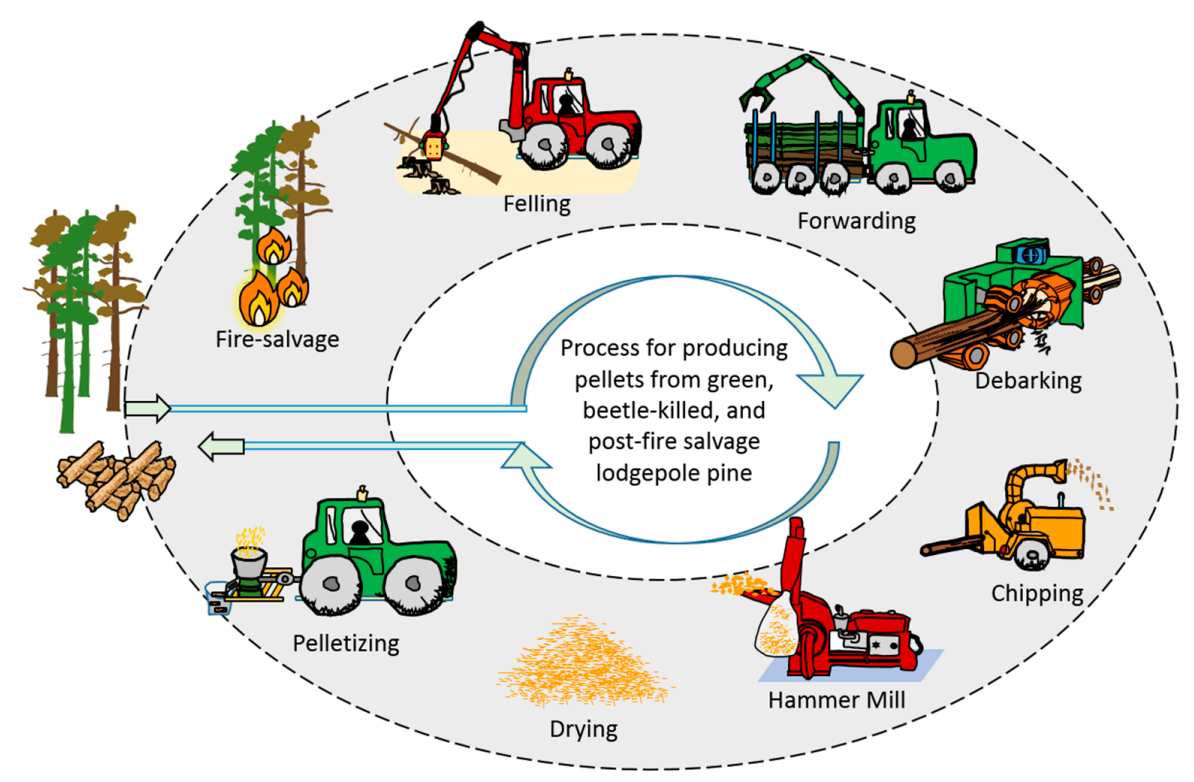

Figure 2. Complete process to produce pellets from post-fire salvage and beetle-killed lodgepole pine using equipment sized for small landowners.

\subsection{Experimental Design}

The experiment was a $2 \times 2 \times 2$ factorial design with three factors: beetle impact (G-green, BK—-beetle-killed), bark (on, off), and fire salvage (B-burn, $\mathrm{N}$ - unburn) (Table 1). Three replications were conducted for each treatment combination. The moisture contents for the raw materials were all kept at approximately $12 \%$ (wet basis) before entering the pellet mill. The temperature and pressure during the pelletizing process were stable. 
Table 1. $2 \times 2 \times 2$ factorial experimental design with three replications for each assortment.

\begin{tabular}{|c|c|c|c|c|c|c|c|}
\hline \multicolumn{4}{|c|}{$\mathrm{G}^{1}$} & \multicolumn{4}{|c|}{ BK $^{2}$} \\
\hline \multicolumn{2}{|c|}{$\mathrm{N}^{3}$} & \multicolumn{2}{|c|}{$\mathrm{B}^{4}$} & \multicolumn{2}{|c|}{$\mathrm{N}$} & \multicolumn{2}{|c|}{ B } \\
\hline Bark On & Bark Off & Bark On & Bark Off & Bark On & Bark Off & Bark On & Bark Off \\
\hline
\end{tabular}

The die was first heated to a desired temperature of approximately $80^{\circ} \mathrm{C}$ by processing a small amount of corn cob debris. After these materials cycled through, sawdust was put into the die and compressed at a speed of 1500 rotations per minute (rpm). Pelletizing was performed using unburned green logs without debarking to adjust the settings of the mill. This setting was used for all other combinations.

For each combination, a sample quantity of $35 \mathrm{~kg}$ of pellets was removed during the pelletizing process. Pellet sampling was performed after the mill was allowed to run for $3 \mathrm{~min}$. For each treatment combination, the percentage of fines was determined using a $3.18 \mathrm{~mm}$ sieve screen, which is the Pellet Fuels Institute (PFI) standard specification. A sample size of $1000 \mathrm{~g}$ of pellets was used to determine the proportion of fines. The quantity of fines was calculated and recorded as the mass of the sample after screening divided by 1000 . Three replicates were used. After separating the fines from pellets, a sample of $25 \mathrm{~kg}$ of pure pellets was sent to Cool Planet Energy Systems for proximate analysis (volatile matter, fixed carbon, and ash), ultimate analysis (C, N, H, O, S), and a combustion test (ash composition analysis). Three replicates were used. The wood fuel properties were determined utilizing American Society for Testing and Materials (ASTM) standards. A final sample of $5 \mathrm{~kg}$ of pure pellets of each assortment were retained for evaluation of mechanical durability, particle density, and calorific value. The mechanical durability and calorific value were determined using the PFI standard specifications for residential/commercial densified fuel [40].

Machine utilization rates for processing equipment in our model system were estimated by using work sampling methods [41]. A sample size of 5 replicates was used to estimate the utilization rate of the chipper, hammer mill, and pellet mill during processing. Machine rates for each piece of equipment that would comprise a complete system with equipment sized for small landowner production of pellets were calculated using methods from Brinker et al. [42], in order to determine fixed and variable components of hourly costs.

\subsection{Pellet Analysis}

The proportion of fines, mechanical durability, particle density, and calorific value were determined at the Washington State University Composite Materials and Engineering Center. Chemical composition, ash content, and combustion tests were conducted by Cool Planet Energy Systems in Camarillo, California. Particle density was determined by averaging five pellet densities for each treatment. The length, diameter, and mass of individual pellets were determined using a Mitutoyo digital caliper (Code 500-171; Mitutoyo Corp., Kawasaki, Japan). The weight was determined using an analytical balance (Fisher Scientific, Waltham, MA, USA). Moisture content was determined in order to calculate dry weight. Particle density was then determined by dividing absolute dry pellet weight by pellet volume.

Mechanical durability was determined using an in-house constructed durability tester built based on PFI Standard Operating Procedure for durability testing. The machine consists of a rectangular plywood box $(305 \mathrm{~mm} \times 305 \mathrm{~mm} \times 140 \mathrm{~mm}$ ) on a $1.5 \mathrm{HP}$ Dayton DC motor (Dayton Electric Manufacturing Company, Niles, IL, USA) and arbor that rotates pellets at a speed of $50 \mathrm{rpm}$. A $500 \mathrm{~g}$ pellet sample without fines was placed into the testing machine. The controlled shocks make the pellets collide against one another and against the walls of the rotating chamber. The sample mass, 
minus the fines, was recorded after 10 min of shocks. The mechanical durability was calculated using the following formula:

$$
\text { Durability }=\mathrm{M} / 500 \times 100 \%
$$

where Durability is mechanical durability and $\mathrm{M}$ is the mass of pellets after treatment. Three replicates for each combination were tested. During the analysis phase, data resulting from the experiment was used to develop a simple model that predicts pellet durability based on all treatment combinations.

Calorific value was determined using a Parr 6200 Calorimeter, Colby College Version standard bomb calorimeter (Parr Instrument Company, Moline, IL, USA). Samples were dried for around $24 \mathrm{~h}$ to absolute dry at $103{ }^{\circ} \mathrm{C}$ prior to testing. For each sample, a single pellet was placed in the bomb calorimeter for analysis. A $10 \mathrm{~cm}$ piece of nickel-chromium fuse wire was attached to the bomb calorimeter and looped down inside the vessel, without touching the pellet or the vessel. The bomb vessel was then pressurized with oxygen to $28 \mathrm{~atm}$. Two liters of deionized water were used to fill in the calorimeter jacket. After that, the bomb canister was submersed in the jacket and two firing wires were connected. Pellet weight was recorded and entered on the unit computer. After $20 \mathrm{~min}$, the calorific value was read from the screen of the calorimeter. The inside of the bomb canister was then cleaned prior to processing the next sample. Three replicates were conducted.

\subsection{Statistical Analysis}

Three-way analysis of variance (ANOVA) and Tukey's multiple comparisons Honest Significant Difference (HSD) test were conducted using the R statistical programming environment to evaluate property differences among treatments. Before fitting the ANOVA, a Shapiro-Wilk Normality test was performed to evaluate the normality of the data for each treatment. Bartlett's test of homogeneity of variances was used to evaluate the equal variance assumption of ANOVA. For data that was non-normal (particle density, nitrogen, sulfur), a Kruskal-Wallis rank sum statistic was used to evaluate the differences between groups.

\section{Results and Discussion}

\subsection{Pellet Properties}

The average diameters of the pellets for different treatment combinations (green ( $\mathrm{g}$ ), beetle-killed (bk), burned (b), unburn (n), bark on (on), and bark off (off)) are shown in Table 2. They were all slightly larger than the diameter of the die hole $(6.00 \mathrm{~mm})$, which indicated that pellets expanded slightly after release from the die. Most pellets had a length shorter than $38 \mathrm{~mm}$, except for $6.96 \mathrm{~g}$ out of $1130 \mathrm{~g}(0.62 \%)$ pellets in the $\mathrm{g} / \mathrm{b} /$ on treatment and $1.33 \mathrm{~g}$ out of $1130 \mathrm{~g}(0.12 \%)$ pellets in the $\mathrm{bk} / \mathrm{b} / \mathrm{off}$ treatment which were longer than $38 \mathrm{~mm}$. All pellets were in PFI Fuel Grade: Premium $(\leq 1.0 \%)$. The maximum lengths of the pellets for the two treatments were $40.88 \mathrm{~mm}$ and $38.57 \mathrm{~mm}$, respectively.

Table 2. Average diameter and particle density (dry basis) of pellets by treatment.

\begin{tabular}{ccccccccc}
\hline Assortment & $\mathbf{g} / \mathbf{n} / \mathbf{o n}$ & $\mathbf{g} / \mathbf{b} / \mathbf{o n}$ & $\mathbf{b k} / \mathbf{n} / \mathbf{o n}$ & $\mathbf{b k} / \mathbf{b} / \mathbf{o n}$ & $\mathbf{g} / \mathbf{n} / \mathbf{o f f}$ & $\mathbf{g} / \mathbf{b} / \mathbf{o f f}$ & $\mathbf{b k} / \mathbf{n} / \mathbf{o f f}$ & $\mathbf{b k} / \mathbf{b} / \mathbf{o f f}$ \\
\hline Diameter $(\mathrm{mm})$ & 6.14 & 6.16 & 6.14 & 6.09 & 6.09 & 6.10 & 6.08 & 6.09 \\
Density $\left(\mathrm{kg} / \mathrm{dm}^{3}\right)$ & 1.16 & 1.13 & 1.12 & 1.15 & 1.19 & 1.16 & 1.12 & 1.20 \\
\hline
\end{tabular}

g: green; bk: beetle-killed; b: burn; n: unburn.

\subsection{Particle Density}

Particle density is an important parameter because it influences pellet bulk density and combustion behavior. Dense particles could increase the burnout time. The average particle densities based on treatments are shown in Table 2. Mass of water in the material was not included (dry basis). Based on the Kruskal-Wallis rank sum test, bark had a significant influence on pellet particle density $(p=0.048)$. Pellets without bark as raw material had higher mean particle density than did bark pellets. 
This result corresponds to previous research [16] and may be an artifact of bark pellets having longer mean length.

\subsection{Mechanical Durability}

Beetle kill, fire salvage, and debarking interactively affected pellet durability, as evident in the bar chart below (Figure 3) and three-way ANOVA test (Table 3). The samples had small mean standard errors overall, with a relatively high standard error for the green/bark on/unburned treatment. After conducting a Tukey's HSD test, the difference in means was evaluated The PFI standard has a three-level standard, with PFI Utility (lowest level) index $\geq 95.0 \%$.

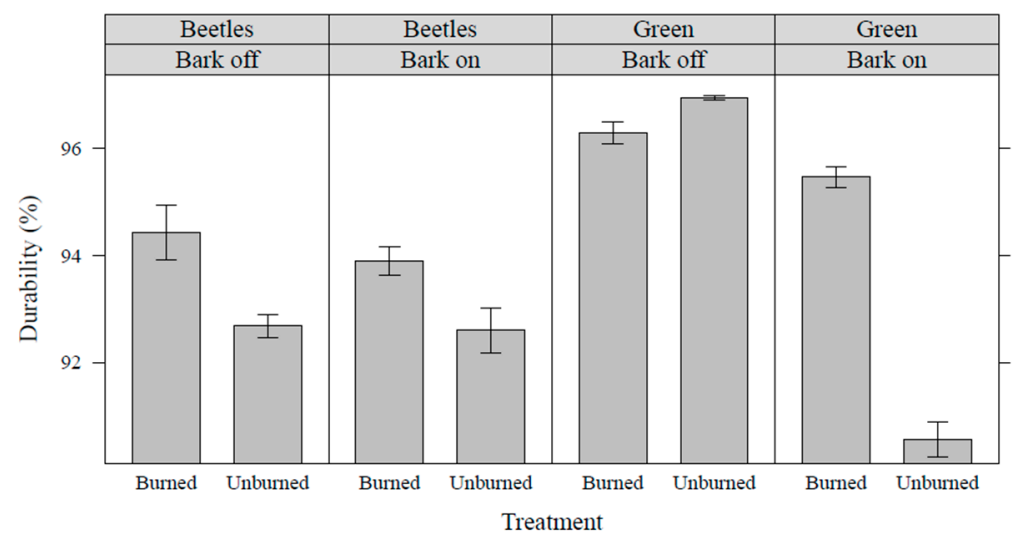

Figure 3. Mean mechanical durability bar chart and standard error of the mean for all assortments.

Table 3. Three-way ANOVA table.

\begin{tabular}{|c|c|c|c|c|c|c|c|}
\hline \multirow{2}{*}{ Summary } & \multicolumn{3}{|c|}{ Factor } & \multicolumn{4}{|c|}{ Interaction } \\
\hline & Beetle & Fire & Bark & Beetle-Fire & Beetle-Bark & Fire-Bark & Beetle-Fire-Bark \\
\hline Degrees of freedom & 1 & 1 & 1 & 1 & 1 & 1 & 1 \\
\hline \multicolumn{8}{|l|}{ Durability } \\
\hline Sum Sq & 12.002 & 19.976 & 22.956 & 0.55 & 16.216 & 9.784 & 13.578 \\
\hline F value & 42.907 & 71.415 & 82.065 & 1.965 & 57.973 & 34.979 & 48.541 \\
\hline$p(>\mathrm{F})$ & $6.68 \times 10^{-6}$ & $2.70 \times 10^{-7}$ & $1.07 \times 10^{-7}$ & 0.18 & $1.05 \times 10^{-6}$ & $2.18 \times 10^{-5}$ & $3.17 \times 10^{-6}$ \\
\hline Significance & $* * *$ & $* * *$ & $* * *$ & - & $* * *$ & $* * *$ & $* * *$ \\
\hline \multicolumn{8}{|l|}{ Heating Value } \\
\hline Sum Sq & 0.1305 & 0.1751 & 0.0092 & 0.0003 & 0.0176 & 0.0063 & 0.242 \\
\hline F value & 20.147 & 27.026 & 1.421 & 0.052 & 2.717 & 0.978 & 37.351 \\
\hline$p(>\mathrm{F})$ & 0.000372 & $8.79 \times 10^{-5}$ & 0.250687 & 0.822357 & 0.118776 & 0.337381 & $1.50 \times 10^{-5}$ \\
\hline Significance & $* * *$ & $* * *$ & - & - & - & - & $* * *$ \\
\hline \multicolumn{8}{|l|}{ Carbon } \\
\hline Sum Sq & 1.485 & 1.898 & 7.583 & 0.002 & 0.32 & 3.565 & 0.008 \\
\hline F value & 1.56 & 1.994 & 7.965 & 0.002 & 0.336 & 3.745 & 0.009 \\
\hline$p(>\mathrm{F})$ & 0.2296 & 0.177 & 0.0123 & 0.9622 & 0.5703 & 0.0708 & 0.9262 \\
\hline Significance & - & - & * & - & - & - & - \\
\hline \multicolumn{8}{|l|}{ Hydrogen } \\
\hline Sum Sq & 0.0067 & 0.132 & 0.5521 & 0.3651 & 0.0121 & 0.1473 & 0.0988 \\
\hline F value & 0.113 & 2.229 & 9.322 & 6.164 & 0.205 & 2.487 & 1.669 \\
\hline$p(>\mathrm{F})$ & 0.74159 & 0.15488 & 0.00759 & 0.02451 & 0.65667 & 0.13437 & 0.21479 \\
\hline Significance & - & - & $* *$ & * & - & - & - \\
\hline \multicolumn{8}{|l|}{ Fuel Yield } \\
\hline Sum Sq & 0.00168 & 0.000247 & 0.00226 & 0.00004 & 0.000135 & 0.00026 & 0.000287 \\
\hline F value & 8.2 & 1.203 & 11.019 & 0.195 & 0.659 & 1.267 & 1.398 \\
\hline$p(>\mathrm{F})$ & 0.01126 & 0.28889 & 0.00434 & 0.66466 & 0.42868 & 0.27699 & 0.2543 \\
\hline Significance & $*$ & - & $* *$ & - & - & - & - \\
\hline
\end{tabular}

Significance codes: $0^{\star * * * \prime} ; 0.001^{* * * \prime} ; 0.01^{* \prime \prime} ;>0.05^{\prime}-^{\prime}$. 
In previous studies, higher concentrations of extractives and lignin in wood have functioned as natural binding agents when pressing pellets $[16,20,25]$, and thus had a positive effect on pellet durability. Wood infested with mountain pine beetle had lower moisture content [27-29] and lower lignin and hemicellulose contents than sound lodgepole pine trees [27]. Since the moisture contents of raw material in our study were all higher than the proper moisture content (12\%) for making pellets, the lower moisture content in MPB-infested wood may not influence the pellet durability much. Therefore, the lower content of lignin in MPB-infested wood should be the key factor that decreased the durability of pellets. Tree bark has higher lignin and extractive content than stem wood; therefore, adding bark may increase the durability of pellets [16]. Fire-killed trees lost moisture content very quickly and thus created a favorable environment for wood rot fungi growth. Brown rot fungi grow on dead cells and break down cellulose and hemicelluloses, but not lignin $[43,44]$. Therefore, brown rot fungi can concentrate lignin [45] and then have positive effects on pellet durability due to the natural binding agents of lignin.

\subsection{Chemical Composition and Calorific Value}

The different elements and calorific values for different assortments are listed in Table 4. C, H, and $\mathrm{O}$ are the main components of biofuels. $\mathrm{C}$ and $\mathrm{H}$ could influence the gross calorific value of the fuel due to exothermic reaction during combustion. Based on our three-way ANOVA test (Table 3) and Tukey's HSD test, adding bark as raw material influenced the C content $(p=0.0123)$ and $\mathrm{H}$ content $(p=0.00759)$ (Table 3$)$ but the change was relatively small. Previous research [16] has shown no difference in $\mathrm{H}$ and $\mathrm{C}$ content between pure wood pellets and pellets with $5 \%$ bark. Fire, beetle kill, and their interactions did not affect $\mathrm{C}$ or $\mathrm{H}$ content, nor did $\mathrm{N}, \mathrm{O}$, or $\mathrm{S}$ content vary among treatments. Although not significant, pellets produced from stem wood with bark on had higher mean quantities of $\mathrm{S}$ and $\mathrm{N}$ than pure wood pellets, which corresponds to previous research [23]. Volatile matter is another factor that may influence the combustion behavior and thermal decomposition of biofuels. However, ANOVA results showed that volatiles did not differ among treatments.

Test results of lignin content (dry basis) are shown in Table 4. Trees that were infested with beetles had lower mean lignin content than green trees (27.83-28.33\%) and trees that were burned had lower mean lignin content than green trees (27.78-28.33\%). However, neither were statistically significant. Beetle infestation did not significantly affect lignin content. The interaction of bark and fire affected lignin content $(p=0.042)$. The investigation of lignin content is very important because lignin binds the material. A more comprehensive study should be undertaken to better explain the differences in durability.

Table 4. Mean of calorific value, proximate, ultimate analysis of wood pellets (wt \% in dry basis).

\begin{tabular}{|c|c|c|c|c|c|c|c|c|c|c|c|}
\hline Group & $\begin{array}{c}\mathrm{MC}^{*} \\
\text { (\% d.b) }\end{array}$ & $\begin{array}{l}\mathrm{CV} * * \\
(\mathrm{MJ} / \mathrm{kg})\end{array}$ & $\begin{array}{c}\text { Ash } \\
(\%)\end{array}$ & $\begin{array}{c}\text { VM *** } \\
(\%)\end{array}$ & $\begin{array}{l}\text { Fixed } \\
\text { Carbon }\end{array}$ & C (\%) & H (\%) & N (\%) & $\mathrm{S}(\%)$ & $\mathrm{O}(\%)$ & $\begin{array}{c}\text { Lignin } \\
\text { (\% Dry) }\end{array}$ \\
\hline $\mathrm{g} / \mathrm{n} / \mathrm{on}$ & 2.51 & 20.69 & 0.30 & 81.33 & 18.37 & 50.49 & 5.86 & 0.34 & 0.12 & 42.89 & 28.4 \\
\hline $\mathrm{g} / \mathrm{b} / \mathrm{on}$ & 5.47 & 20.29 & 0.39 & 82.68 & 16.93 & 50.45 & 5.73 & 0.31 & 0.10 & 42.80 & 28.2 \\
\hline $\mathrm{bk} / \mathrm{n} / \mathrm{on}$ & 2.60 & 20.59 & 0.37 & 81.48 & 18.15 & 49.75 & 5.82 & 0.36 & 0.09 & 43.62 & 27.4 \\
\hline $\mathrm{bk} / \mathrm{b} / \mathrm{on}$ & 1.65 & 20.57 & 0.35 & 81.21 & 18.43 & 49.97 & 5.93 & 0.32 & 0.11 & 43.32 & 27.8 \\
\hline $\mathrm{g} / \mathrm{n} / \mathrm{off}$ & 2.69 & 20.36 & 0.35 & 81.90 & 17.75 & 52.12 & 5.57 & 0.25 & 0.06 & 41.64 & 28.8 \\
\hline $\mathrm{g} / \mathrm{b} / \mathrm{off}$ & 3.57 & 20.43 & 0.32 & 81.69 & 17.99 & 50.84 & 5.50 & 0.21 & 0.06 & 43.06 & 27.9 \\
\hline $\mathrm{bk} / \mathrm{n} / \mathrm{off}$ & 3.49 & 20.77 & 0.33 & 81.49 & 18.18 & 51.91 & 5.18 & 0.23 & 0.07 & 42.28 & 29.0 \\
\hline $\mathrm{bk} / \mathrm{b} / \mathrm{off}$ & 2.52 & 20.43 & 0.27 & 81.30 & 18.43 & 50.52 & 5.86 & 0.28 & 0.11 & 42.97 & 27.2 \\
\hline
\end{tabular}

${ }^{*} \mathrm{MC}$ : moisture content; ${ }^{* *} \mathrm{CV}$ : calorific value; ${ }^{* * *} \mathrm{VM}$ : volatile matter.

Pellets produced with bark had higher $\mathrm{N}$ concentrations than those produced with pure wood [23]. The presence of $\mathrm{N}$ and $\mathrm{S}$ could cause gaseous emissions $\left(\mathrm{SO}_{\mathrm{x}}\right.$ and $\mathrm{NO}_{\mathrm{x}}$ ), which may cause environmental impacts associated with biofuel combustion [46]. Usually, biofuels with lower than $0.6 \% \mathrm{~N}$ and lower than $0.2 \% \mathrm{~S}$ do not cause emission problems [47]. All eight treatment combinations in this study had less than $0.4 \% \mathrm{~N}$ and less than $0.2 \% \mathrm{~S}$, so pellets with bark as raw material, pellets 
produced from fire-salvaged stem wood, and those produced from beetle-killed wood would not cause emission problems.

Three-way ANOVA and Tukey's HSD results indicated that beetle kill $(p=0.00037)$ and fire salvage $\left(p=8.79 \times 10^{-5}\right)$ differed in the calorific values for pellets. Pellets made with beetle-infested wood had slightly higher mean calorific value than those made with green wood $(20.59-20.44 \mathrm{MJ} / \mathrm{Kg})$. This differs from prior results showing no significant difference but increased mean heating values for MPB than pellets made from uninfested pine (19.20-19.05 MJ/Kg) [26]. Pellets made with burned materials had lower mean calorific value than those made with unburned material (20.43-20.59 MJ/Kg), though the difference was small. This differs from results in Mackes and Jennings [10] that showed no difference of calorific value between pellets made with burned and unburned materials. The discrepancy may due to the higher standard deviation reported in their data. Our study had lower variability in calorific values measured.

Pellets produced from wood with bark on and bark off using equipment sized for small landowners did not differ in calorific value. This differs from previous studies $[16,21]$ that have shown increasing calorific value varying directly with bark content because of the higher calorific value of bark. Bark has higher contents of extractives and lignin and they have higher calorific values than cellulose [21,22]. We tested the bark ratio for each assortment by randomly sampling five small pieces of stems; we then dried them in an oven until absolute dry, debarked them, and then weighed the bark and wood separately. The bark ratio ranged from $0 \%$ to $3.21 \%$, which is a small quantity compared to wood. Even though the heating value of bark is higher than wood, it reasonably makes less of a contribution to the heating value of overall stem biomass (stem wood plus bark) because of the relatively small proportion of feedstock it represents [21].

\subsection{Ash Content}

The ash content of pellets produced with bark did not differ significantly from the ash content of pellets produced without bark. These results are similar to the results of Filbakk et al. [16], which indicated that the ash content of pure bark pellets was more than five times higher than that of pure wood but there was little or no difference between the two when bark ratio was less than $5 \%$. All the raw materials in this paper have less than $5 \%$ bark ratio, which corresponded to no difference in ash content between pellets with and without bark.

Similarly, fire also did not affect the ash content of pellets. From previous research, fire-salvaged trees with large proportions of charcoal on the trunk and wood decay may increase the ash content of pellets [30]. Area proportions of charcoal on the surface of trunk in this paper ranged from $56 \%$ to $99 \%$. However, most stem wood under the inner bark was not exposed to combustion. The quantities of charcoal may not have been large enough to cause a difference in subsequent pellet ash content. In the context of producing pellets from salvage logging operations, the magnitude of this effect is likely to vary with the intensity of wildland fires.

\subsection{Anticipated Fuel Yield of Base}

Cool Planet Energy Systems uses a model to predict fuel yield as a function of feedstock cellulose, lignin, and hemicellulose content. Fuel yield is the mass yield of field-measured values relative to the bone-dry feedstock quantity. The results are ratios of the fuel yield compared to their base production from the base feedstock. Results showed that all treatment combinations resulted in high predicted yields, from $96 \%$ to $100 \%$ of the optimized baseline fuel yield from pine. This indicates that MPB-killed lodgepole pine, fire-salvaged lodgepole pine, and lodgepole pine with bark on are all suitable materials for producing high-quality pellets as an interim step in biofuel production. Bark statistically decreased the fuel yield ( $p=0.00434)$ but only to a minor extent $(1.9 \%)$ (Table 3$)$. 


\subsection{Machine Rate}

Machine rates were estimated for the following harvest system. We assume a tractor with a hydraulic felling head was used to cut and process stems. The operators were given several days to gain experience in operating the machines. The utilization rates for the small-scale chipper, hammer mill, and pellet mill used in the study were estimated using work sampling. The utilization rates for the feller, forwarder, and debarker were assumed to be $80 \%, 80 \%$, and $75 \%$, respectively. The utilization rates for the chipper, hammer mill, and pellet mill were estimated as $57 \%, 60 \%$, and $72 \%$, respectively. The utilization rate for the chipper was low primarily because of frequent manual changing of containers used to transport chips to the hammer mill. Chips produced from the chipper were loaded into containers to store properly. When the requisite volume of chips was produced, the chipper was stopped, and another container was positioned to replace it. The machine rates, which are estimates of the lifetime average hourly owning and operating costs for each piece of equipment in the complete small-scale harvesting system, are shown in Table 5. The price of the cutting head by itself in this system was assumed to be U.S. $\$ 75,000$ and the price of the tractor and forwarder trailer were assumed to be U.S. $\$ 125,000$. Several assumptions were made for the cost analysis, including (1) economic life of 5 years for all equipment in the system; (2) 10\% interest rate on loans; (3) $20 \%$ salvage rate (residual value at end of life); (4) fuel cost of $\$ 11.36 / \mathrm{L}$. Fixed costs of ownership and variable costs of operation are included in Table 5. Machine rate calculations allow landowners to compare the economics of specified machines used in pellet production and make economic comparisons between these and other equipment alternatives.

Table 5. Machine rate for tractor-mounted felling head, tractor and forwarder trailer, debarker, chipper, hammer mill, and pellet mill.

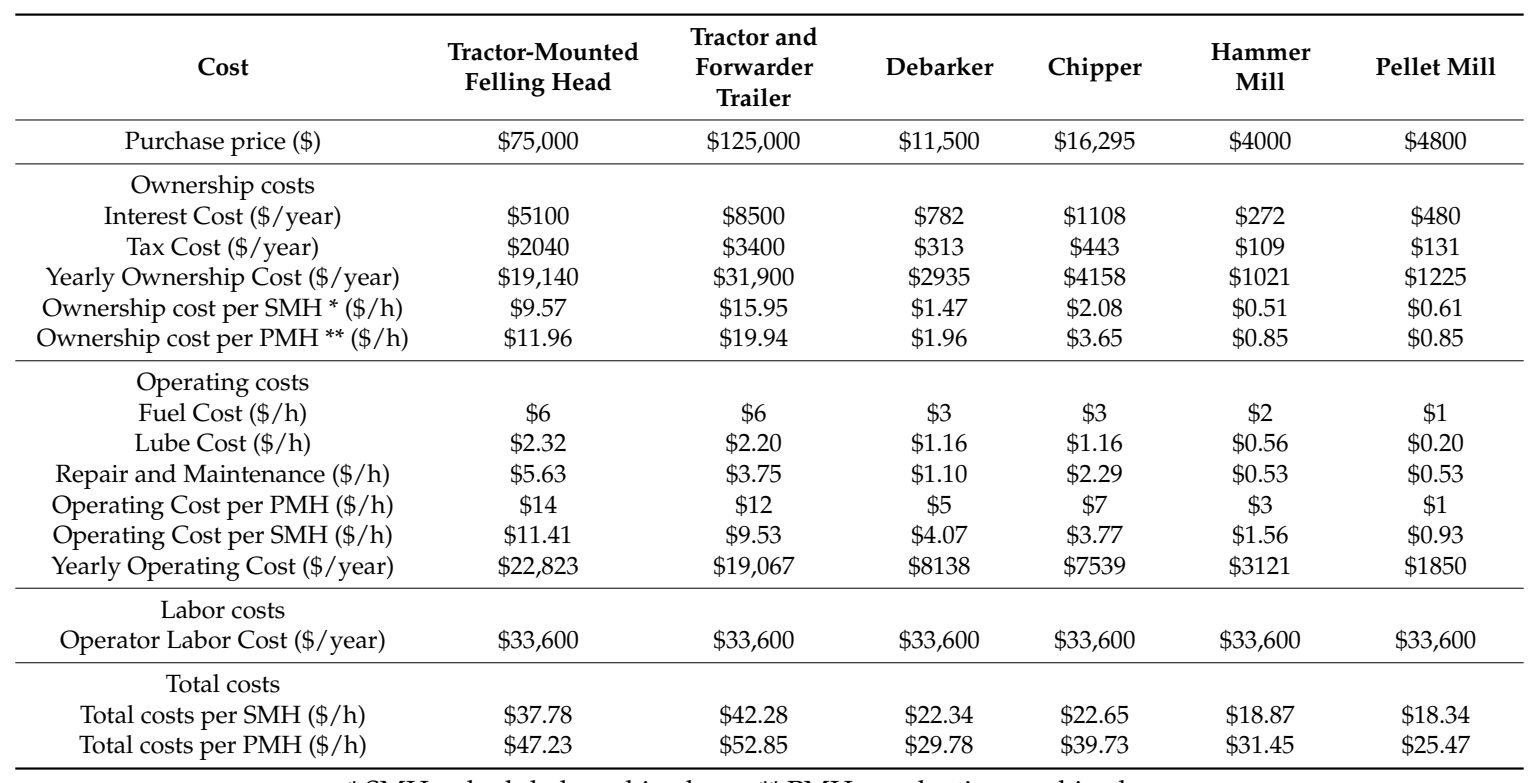

* SMH: scheduled machine hour; ${ }^{* *} \mathrm{PMH}$ : productive machine hour.

Production rates for the equipment in the system were not estimated, so it was not possible to compare capital costs per ton with estimates from previous studies. However, once landowners know the production rates of the equipment, unit cost $\left(\$ /\right.$ ton or $\left.\$ / \mathrm{m}^{3}\right)$ could be easily calculated based on the estimates of machine rates provided in this paper. The $\$ 47.23$ /productive machine hour (PMH) cost of the tractor and felling head attachment is lower than the $\$ 51.73 / \mathrm{PMH}$ for a small excavator with a Fecon shear head feller [6]. The cost of chipping using the small, $46 \mathrm{HP}$ chipper in this study was $\$ 39.73 / \mathrm{PMH}$, which is approximately $75 \%$ lower than the $\$ 130.86 / \mathrm{PMH}$ for a much larger 325 HP Morbark Typhoon chipper [6]. The cost of transportation is dependent upon the distance from 
the stand to the facility and was not estimated in this study. Total costs to operate the system were calculated to be $\$ 162.26$ per scheduled machine hour (SMH) and $\$ 226.51 / \mathrm{PMH}$.

For all feedstock sources, new advances in technology—particularly real-time data sharing for operational forestry-will help to quantify and optimize logistics in green, beetle kill, and post-fire salvage operations in the future, in order to help reduce the primary harvesting and processing costs of biomass operations [48]. It is important to note that although it was not explicitly estimated in this study, there may be variability in costs associated with air-drying or tumble-drying of feedstock (whether logs, chips, or sawdust) for the different sources considered, and drying may also affect logistics, costs, and uniformity of the different feedstocks considered [15,49].

\section{Conclusions}

In conclusion, the results suggest that green, beetle-killed, and fire-salvaged lodgepole pine produced with small landowner equipment are all suitable for wood pellet production either as a product used directly for home heat and power, for international export, or as an interim feedstock for subsequent wood-based biofuel production. A new biofuel facility built in the Northern Rocky Mountain Region of the United States could successfully alternate among feedstock sources associated with different lodgepole pine stand management trajectories using all three feedstock sources (green, beetle kill, burned). These alternate feedstocks may be associated with different levels of management by small landowners, or from feedstocks associated with different management strategies represented on the landscape among private, industrial, state, and federal forest management. If landowners are actively managing lodgepole pine stands through thinning and regular harvesting operations, more green wood and logging residues may generally be available for pellet production. If forest health and restoration treatments are implemented in beetle-killed stands in nonindustrial private forests (NIPF), then more beetle-killed stem wood is likely to become available to produce pellets, which in turn can be utilized in biofuel production when needed to meet feedstock demand. If little management is done, then additional fire-salvaged wood may ultimately become available following wildland fire. In a distributed feedstock model, the relative proportions of these sources may vary both spatially and over time, and production from blended sources may be a useful supply strategy in the Northern Rockies in the future.

Beetle infestation, fire salvage, and bark all influenced pellet mechanical durability. Beetle-killed pellets had slightly lower mean durability than green pellets, while bark and fire salvage pellets had higher mean durability. Differences are primarily due to the different lignin and extractive content of bark. Some of the pellet combinations (g/n/on, g/b/on, and g/b/off) meet the PFI Utility requirement. Pellets that included bark materials had slightly lower mean particle density than wood pellets. Bark had no effect on calorific value relative to pure stem wood. The mean calorific value of beetle-killed pellets was higher than that of green wood pellets while the mean calorific value of burned pellets was lower than that of unburned pellets. All assortments were well within the levels given in the European Committee for Standardization (CEN) standards. All three factors may not have an influence on slag and hard deposit formation in boilers due to similar and low contents of $S$ and $N$. Ash contents were similar and all assortments were in the best quality class in the CEN standards. These results all suggest that regardless of stand history, lodgepole pine from healthy, treated, or even post-fire salvage stands provides suitable feedstock for wood-based biofuel production in a distributed system that varies in feedstock sources over time and incorporates small landowners into landscape-scale production and feedstock supply models.

Acknowledgments: This research was funded by USDA Agriculture and Food Research Initiative Coordinated Agricultural Project (CAP) Bioenergy Alliance Network of the Rockies Competitive Grant No. 2013-68005-21298. Undergraduate research technicians Lance Johnson, Ryan Spaniel, and Molly Rard assisted with pellet production and sampling at the Forest Operations Research Laboratory. 
Author Contributions: Xuexian Qin and Robert Keefe conceived of the manuscript idea and designed the experiments; Xuexian Qin performed the experiments and analyzed the data; Daren Daugaard conducted sample analysis and modeling; Xuexian Qin, Robert Keefe, and Daren Daugaard wrote and revised the paper.

Conflicts of Interest: The authors declare no conflict of interest.

\section{References}

1. Hosegood, S.; Leitch, M.; Shahi, C.; Pulkki, R. Moisture and energy content of fire-burnt trees for bioenergy production: A case study of four tree species from northwestern Ontario. For. Chron. 2011, 87, 42-47. [CrossRef]

2. USDA Forest Services FHTET Pest Portal. Available online: https://foresthealth.fs.usda.gov/portal/ (accessed on 1 October 2015).

3. Government of Canada Mountain Pine Beetle (Factsheet). Available online: http://www.nrcan.gc.ca/ forests / fire-insects-disturbances/top-insects/13397 (accessed on 5 March 2018).

4. Bogdanski, B.; Sun, L.; Peter, B.; Stennes, B. Markets for Forest Products Following a Large Disturbance: Opportunities and Challenges from the Mountain Pine Beetle Outbreak in Western Canada-Information Report; Canadian Forest Service Publications: Victoria, BC, Canada, 2011; ISBN 9781100182865.

5. Collins, B.J.; Rhoades, C.C.; Battaglia, M.A.; Hubbard, R.M. The effects of bark beetle outbreaks on forest development, fuel loads and potential fire behavior in salvage logged and untreated lodgepole pine forests. For. Ecol. Manag. 2012, 284, 260-268. [CrossRef]

6. Yu, A.; Gallagher, T.; Mitchell, D.; O’Neal, B. Application of a Small-Scale Equipment System for Biomass Harvesting. Small Scale For. 2017, 16, 133-146. [CrossRef]

7. Taylor, S.W.; Carroll, A.L. Mountain Pine Beetle Symposium: Challenges and Solutions BC-X-399; Canadian Forest Service Publications: Victoria, BC, Canada, 2004; ISBN 0662383893.

8. Cole, W.E.; Amman, G.D. Mountain Pine Beetle Dynamics in Lodgepole Pine Forests Part 1: Course of an Infectation; INT-89; United States Department of Agriculture Forest Service: Washington, DC, USA, 1980; pp. 1-63.

9. Watson, P.; Potter, S. Burned wood in the pulp and paper industry: A literature review. For. Chron. 2004, 80, 473-477. [CrossRef]

10. Mackes, K.; Jennings, C. Evaluating the heating value of fire-killed ponderosa pine trees in Colorado. For. Prod. J. 2008, 58, 53-55.

11. Barrette, J.; Thiffault, E.; Paré, D. Salvage harvesting of fire-killed stands in Northern Quebec: Analysis of bioenergy and ecological potentials and constraints. J. Sci. Technol. For. Prod. Process. 2013, 3, 16-25.

12. Jacobson, R.A.; Keefe, R.F.; Smith, A.M.S.; Metlen, S.; Saul, D.A.; Newman, S.M.; Laninga, T.J.; Inman, D. Multi-spatial analysis of forest residue utilization for bioenergy. Biofuels Bioprod. Biorefin. 2016, 10, 560-575. [CrossRef]

13. Oswalt, S.; Thompson, M.; Smith, W.B. U.S. Forest Resource Facts and Historical Trends; FS-801, 60, FS-1035; United States Department of Agriculture Forest Service: Washington, DC, USA, 2014.

14. Newman, S.; Saul, D.; Keefe, R.; Jacobson, R.; Laninga, T.; Moroney, J. “The Devil Is in the Details”: Inland Northwest Stakeholders' Views on Three Forest-Based Bioenergy Scenarios. For. Sci. 2017, 63, 614-620.

15. Keefe, R.; Anderson, N.; Hogland, J.; Muhlenfeld, K. Woody Biomass Logistics. Cellul. Energy Crop. Syst. 2014, 251-279. [CrossRef]

16. Filbakk, T.; Jirjis, R.; Nurmi, J.; Høibø, O. The effect of bark content on quality parameters of Scots pine (Pinus sylvestris L.) pellets. Biomass Bioenergy 2011, 35, 3342-3349. [CrossRef]

17. Melin, S. Bark as Feedstock for Production of Wood Pellets; Wood Pellet Association of Canada: Revelstoke, BC, Canada, 2008.

18. Rhén, C.; Öhman, M.; Gref, R.; Wästerlund, I. Effect of raw material composition in woody biomass pellets on combustion characteristics. Biomass Bioenergy 2007, 31, 66-72. [CrossRef]

19. Öhman, M.; Boman, C.; Hedman, H.; Nordin, A.; Boström, D. Slagging tendencies of wood pellet ash during combustion in residential pellet burners. Biomass Bioenergy 2004, 27, 585-596. [CrossRef]

20. Lehtikangas, P. Quality properties of pelletised saw dust, lgging residues and bark. Biomass Bioenergy 2001, 20, 351-360. [CrossRef]

21. Nurmi, J. Heating values of the above ground biomass of small-sized trees. Acta For. Fenn. 1993, $236,1-30$. [CrossRef] 
22. Nurmi, J. Heating Values of Mature Trees. Acta For. Fenn. 1997, 256, 1-28. [CrossRef]

23. Obernberger, I.; Thek, G. Physical characterisation and chemical composition of densified biomass fuels with regard to their combustion behaviour. Biomass Bioenergy 2004, 27, 653-669. [CrossRef]

24. Toscano, G.; Riva, G.; Foppa Pedretti, E.; Corinaldesi, F.; Mengarelli, C.; Duca, D. Investigation on wood pellet quality and relationship between ash content and the most important chemical elements. Biomass Bioenergy 2013, 56, 317-322. [CrossRef]

25. Bradfield, J.; Levi, M. Effect of species and wood to bark ratio on pelleting of Southern woods. For. Prod. J. 1984, 34, 61-63.

26. Zaini, P.; Sokansanj, S.; Bi, X.; Lim, C.J.; Mani, S.; Melin, S.; Kadla, J. Density, heating value, and composition of pellets made from lodgepole pine (Pinus concorta Douglas) infested with mountain pine beetle (Dendroctonus ponderosae hopkins). Can. Biosyst. Eng. 2008, 50, 3.47-3.55.

27. Woo, K.L.; Watson, P.; Mansfield, S.D. The effects of mountain pine beetle attack on lodgepole pine wood morphology and chemistry: Implications for wood and fiber quality. Wood Fiber Sci. 2005, 37, 112-126.

28. Lewis, K.; Hartley, I. Rate of deterioration, degrade, and fall of trees killed by mountain pine beetle. J. Ecosyst. Manag. 2006, 7, 11-19.

29. Trent, T.; Lawrence, V.; Woo, K. A Wood and Fibre Quality-Deterioration Model for Mountain Pine Beetle-Killed Trees by Biogeoclimatic Subzone; Canadian Forest Service Publications: Victoria, BC, Canada, 2006.

30. Bushnell, D.J. Bıomass Fuel Charecterization: Testing and Evaluating the Combustion Characteristics of Selected Bıomass Fuels; U.S. Department of Energy Office of Scientific and Technical Information: Oak Ridge, TN, USA, 1989.

31. Arshadi, M.; Gref, R.; Geladi, P.; Dahlqvist, S.A.; Lestander, T. The influence of raw material characteristics on the industrial pelletizing process and pellet quality. Fuel Process. Technol. 2008, 89, 1442-1447. [CrossRef]

32. Carone, M.T.; Pantaleo, A.; Pellerano, A. Influence of process parameters and biomass characteristics on the durability of pellets from the pruning residues of Olea europaea L. Biomass Bioenergy 2011, 35, 402-410. [CrossRef]

33. Rhén, C.; Gref, R.; Sjöström, M.; Wästerlund, I. Effects of raw material moisture content, densification pressure and temperature on some properties of Norway spruce pellets. Fuel Process. Technol. 2005, 87, 11-16. [CrossRef]

34. Mani, S.; Tabil, L.G.; Sokhansanj, S. Effects of compressive force, particle size and moisture content on mechanical properties of biomass pellets from grasses. Biomass Bioenergy 2006, 30, 648-654. [CrossRef]

35. Gaitán-Alvarez, J.; Moya, R.; Puente-Urbina, A.; Rodriguez-Zuñiga, A. Physical and Compression Properties of Pellets Manufactured with the Biomass of Five Woody Tropical Species of Costa Rica Torrefied at Different Temperatures and Times. Energies 2017, 10, 1205. [CrossRef]

36. Kaliyan, N.; Morey, R.V. Natural binders and solid bridge type binding mechanisms in briquettes and pellets made from corn stover and switchgrass. Bioresour. Technol. 2010, 101, 1082-1090. [CrossRef] [PubMed]

37. Kaliyan, N.; Vance Morey, R. Factors affecting strength and durability of densified biomass products. Biomass Bioenergy 2009, 33, 337-359. [CrossRef]

38. Larsson, S.H.; Thyrel, M.; Geladi, P.; Lestander, T.A. High quality biofuel pellet production from pre-compacted low density raw materials. Bioresour. Technol. 2008, 99, 7176-7182. [CrossRef] [PubMed]

39. Paulrud, S. Upgraded Biofuels_Effects of Quality on Processing, Handling Characteristics, Combustion and Ash melting; Swedish University: Umea, Sweden, 2004.

40. PFI Pellet Fuels Institute Standard Specification for Residential/Commercial Densified Fuel. Available online: http:/ / www.pelletheat.org/assets/docs/2015/Standards/standard\%20specification\%20july\%209\% 202015.pdf (accessed on 1 February 2016).

41. Miyata, E.S. Determining Fixed and Operating Costs of Logging Equipment; General Technical Report NC-55; United States Department of Agriculture Forest Service: Washington, DC, USA, 1980; pp. 1-20.

42. Brinker, R.; Miller, D.; Stokes, B.; Lanford, B. Machine Rates for Selected Forest Harvesting Machines; Circular 296; Alabama Agriculture Experimental Station: Auburn, AL, USA, 2002.

43. Schmidt, O. Wood and Tree Fungi: Biology, Damage, Protection, and Use; Springer: Hamburg, Germany, 2006; ISBN 9783540321392.

44. Moore, D. Fungal Biology in the Origin and Emergence of Life; Cambridge University Press: Cambridge, UK, 2013. 
45. Rayner, A.D.M.; Boddy, L. Fungal Decomposition of WOod. Its Biology and Ecology; John Wiley \& Sons Ltd.: Chichester, UK, 1988; ISBN 0471103101.

46. Leckner, B.; Karlsson, M. Gaseous emissions from circulating fluidized bed combustion of wood. Biomass Bioenergy 1993, 4, 379-389. [CrossRef]

47. Obernberger, I.; Brunner, T.; Barnthaler, G. Chemical properties of solid biofuels-significance and impact. Biomass Bioenergy 2006, 30, 973-982. [CrossRef]

48. Becker, R.M.; Keefe, R.F.; Anderson, N.M. Use of real-time GNSS-RF Data to characterize the swing movements of forestry equipment. Forests 2017, 8, 1-15. [CrossRef]

49. Saralecos, J.D.; Keefe, R.F.; Tinkham, W.T.; Brooks, R.H.; Smith, A.M.S.; Johnson, L.R. Effects of harvesting systems and bole moisture loss on weight scaling of douglas-fir sawlogs (Pseudotsuga Menziesii var. glauca Franco). Forests 2014, 5, 2289-2306. [CrossRef]

(C) 2018 by the authors. Licensee MDPI, Basel, Switzerland. This article is an open access article distributed under the terms and conditions of the Creative Commons Attribution (CC BY) license (http://creativecommons.org/licenses/by/4.0/). 